\title{
POTENSI PEMANFAATAN LIGNOSELULOSA DARI BIOMASA KAYU KARET (Hevea brasisiliensis Muell Arg.)
}

\author{
Potential Use of Lignocellulose Rubber Wood Biomass (Hevea brasiliensis Muell Arg.) \\ Lestari Admojo dan Budi Setyawan \\ Balai Penelitian Getas, J1. Pattimura Km.6 Salatiga 50721 \\ Email : tariadmojo@gmail.com
}

Diterima 7 Maret 2018 / Direvisi 3 Mei 2018 / Disetujui 10 Juli 2018

\begin{abstract}
Abstrak
Tanaman karet (Hevea brasiliensis) merupakan salah satu tanaman perkebunan utama yang cukup diandalkan di Indonesia. Luas areal karet di Indonesia sampai tahun 2016 mencapai 3,6 juta hektar. Tanaman karet memiliki umur ekonomis sekitar 25 - 30 tahun, sebelum akhirnya direplanting. Produksi kayu karet yang dihasilkan di akhir masa sadapnya merupakan salah satu biomassa potensial dengan kandungan lignoselulosa yang cukup tinggi. Lignoselulosa merupakan komponen polisakarida yang mengandung selulosa, hemiselulosa dan lignin yang berpotensi untuk diproses menjadi produk tertentu, seperti bioetanol, biogas, minyak berbasis biomasa (bio-oil), bioarang, hingga pemanfaatan selulosa yang berukuran nano (nanoselulosa) untuk kebutuhan industri elektronik, manufaktur dan otomotif. Lignoselulosa dari biomassa kayu karet antara lain dapat dimanfaatkan untuk menghasilkan sumber energi (bioetanol), pendukung sarana pertanian (bioarang, biopestisida, pupuk), industri obat dan makanan (vanilin, zat tambahan makanan, bahan kemasan) dan nanoselulosa. Produk berbahan dasar biomassa akan mendukung industri masa depan yang terbarukan, mudah terdegradasi dan lebih ramah lingkungan.
\end{abstract}

Kata kunci: kayu karet, biomassa, Hevea brasiliensis, lignoselulosa, bioetanol

\begin{abstract}
Rubber tree (Hevea brasiliensis) is a major industrial crop in Indonesia. Rubber plantation in Indonesia covers to an estimated area of 3.6 million hectares in 2016. Rubber has an economic cycle about 25 - 30 years, then removed and replanted. Rubberwood is one of potential biomass with high lignocellulose content. Lignocellulose is a polysaccharide compound consisting of cellulose, hemicellulose and lignin which could be utilized for future products, such as bioethanol, biogas, bio-oil, biochar, also nanomaterial product called nanocellulose for electronics, manufactured and automotif compounds. Utilization of lignocelluloses derived from rubber wood has been widely studied, particularly for the bioenergy (bioethanol), agricultural products (biochar, biopesticide, biofertilizer) medical and food industry (vanillin, food additives packaging) and nanocellulose. All of biomass derived product support future industrial product that are renewable, biodegradable and environmentally friendly.
\end{abstract}

Keywords: rubber wood, biomass, Hevea brasiliensis, lignocellulose, bioethanol

\section{Pendahuluan}

Tanaman karet (Hevea brasiliensis) merupakan salah satu tanaman perkebunan utama yang cukup diandalkan di Indonesia. Luas areal karet di Indonesia hingga tahun 2016 mencapai 3,6 juta hektar (Direktorat 
Jenderal Perkebunan, 2016). Luas areal tersebut sebagian besar terdapat di enam provinsi dengan kontribusi kumulatif mencapai $73,86 \%$, yaitu Sumatera Selatan, Sumatera Utara, Riau, Jambi, Kalimantan Barat, dan Kalimantan Tengah (Kementerian Pertanian, 2016). Tanaman karet memiliki umur ekonomis sekitar 25 - 30 tahun, sebelum akhirnya diremajakan. Tanaman karet berpotensi menghasilkan kayu pada akhir masa sadapnya, yang merupakan salah satu biomasa potensial dengan kandungan lignoselulosa yang cukup tinggi. Lignoselulosa merupakan bagian biomasa tanaman yang berpotensi untuk diproses menjadi produk tertentu, seperti bioetanol, biogas, bio-oil, bioarang, hingga pemanfaatan selulosa yang berukuran nano (nanoselulosa) untuk kebutuhan industri elektronik, manufaktur dan otomotif.

Lignoselulosa merupakan senyawa polisakarida yang terdiri atas selulosa, hemiselulosa dan lignin. Selulosa dan hemiselulosa termasuk polimer karbohidrat (polimer gula). Lignin adalah polimer aromatik yang dapat digunakan untuk memproduksi beberapa bahan kimia. Tingkatan pasar dari produk lignoselulosa bisa sangat luas. Ruamsook \& Thomchick (2014) telah mereview tingkatan pasar produk hasil dari lignoselulosa yang meliputi pasar tingkat 1 berupa biomasa tanaman (biomass crop assistance); pasar tingkat - 2 berupa bioenergi maju (bioenergy for advanced biofuels); pasar tingkat - 3 berupa produk turunan dari bioenergi (biorefinery, renewable chemical, and bio-based product manufacturing assistance); hingga pasar tingkat - 4 berupa produk berbasis biomasa (bio-based markets). Sumber utama selulosa adalah serat dan kayu, yang merupakan biomasa yang terbarukan, berkelanjutan dan sumber biofuel dan monomer yang bebas karbon.

Potensi pemanfaatan lignoselulosa yang berasal dari kayu karet tua perlu dikaji lebih jauh, terlebih kebutuhan industri masa depan yang mengutamakan bahan baku yang terbarukan dan berkelanjutan, di samping untuk memelihara kelestarian lingkungan. Tulisan ini bertujuan untuk mengetahui lebih jauh potensi pemanfaatan lignoselulosa dari biomasa kayu karet. Pemanfaatan tersebut meliputi potensinya untuk bioenergi, bahan pertanian, industri pangan dan obat-obatan serta nanomaterial. Informasi tersebut dapat digunakan sebagai wacana awal untuk melihat potensi pemanfaatan kayu karet tua untuk industri di masa depan.

\section{Potensi Biomasa Kayu Karet}

Volume log kayu karet dengan diameter diatas $15 \mathrm{~cm}$ berkisar antara $52 \mathrm{~m}^{3} /$ ha hingga $162 \mathrm{~m}^{3} /$ ha, biasanya dapat dipanen hingga 100 - $200 \mathrm{~m}^{3} /$ ha. Volume kayu per hektar tergantung beberapa faktor seperti jenis klon, lingkungan tumbuh, teknik budidaya dan pemeliharaan tanaman. Total volume kayu karet di wilayah ASEAN diperkirakan mencapai 17 juta $\mathrm{m}^{3}$ (Killmann, 2001). Menggunakan asumsi peremajaan untuk setiap tahunnya sebesar $5 \%$, maka potensi kayu karet secara nasional sekitar 34,50 juta $\mathrm{m}^{3} /$ tahun (Woelan et al., 2012). Studi kasus di Sumatera Selatan, apabila diasumsikan areal peremajaan hanya $30 \mathrm{ha} /$ desa dan dari setiap hektar kebun karet tua dihasilkan kayu karet sebanyak 60 ton atau $40 \mathrm{~m}^{3}$, maka dari luas peremajaan seluas 28.650 ha akan diperoleh potensi kayu karet setiap tahun mencapai 1,7 juta $\mathrm{m}^{3}$ atau 1,1 juta ton (Nancy et al., 2013). Sebanyak $29.950 \mathrm{~kg} / \mathrm{ha}$ selulosa dari material bahan tanam karet yang tidak digunakan dapat menghasilkan sekitar $15.213 \mathrm{~kg}$ etanol per ha dan 304 juta kg etanol per 20,000 ha dari area peremajaan (Razar \& Aris, 2012). Data BPS menunjukkan potensi kayu karet pada tahun 2015 mencapai 500.512,08 $\mathrm{m}^{3}$ (Badan Pusat Statistik, 2015).

Potensi biomasa dan energi dari kayu karet di Indonesia memiliki nilai yang cukup besar dibandingkan dengan beberapa biomasa 
lainnya (Tabel 1). Secara nasional, biomasa kayu karet tua cukup potensial untuk dimanfatkan menjadi sumber energi, dapat mencapai $120 \mathrm{GJ} /$ tahun (Abdullah, 2002). Potensi biomasa nasional berdasarkan ketersediaan bahan baku dan sumber energi secara disajikan pada Tabel 2. Data menunjukkan bahwa kayu karet tua menjadi salah satu biomasa yang sangat potensial untuk memenuhi kebutuhan bioenergi nasional (Tabel 2). Potensi 1 GJ setara dengan $278 \mathrm{kWh}$ (kiloWatt-hour).

Tabel 1. Potensi energi dari biomasa industri pertanian daerah utama di Indonesia

\begin{tabular}{|c|c|c|c|c|}
\hline Biomasa & $\begin{array}{l}\text { Daerah } \\
\text { Utama }\end{array}$ & $\begin{array}{c}\text { Produksi } \\
\text { (juta ton/ tahun) }\end{array}$ & $\begin{array}{l}\text { Potensi energi } \\
\text { (GJ/tahun) }\end{array}$ & Catatan \\
\hline Karet & $\begin{array}{l}\text { Sumatera, } \\
\text { Kalimantan, } \\
\text { Jawa }\end{array}$ & 41 & 120 & $\begin{array}{l}\text { Batang kecil } \\
\mathrm{D}<10 \mathrm{~cm} \text {, batang } \\
\text { besar dan } \\
\text { medium biasanya } \\
\text { untuk kayu bakar }\end{array}$ \\
\hline $\begin{array}{l}\text { Sisa kayu } \\
\text { gergajian }\end{array}$ & $\begin{array}{l}\text { Sumatera, Jawa, } \\
\text { Kalimantan }\end{array}$ & 1,3 & 13 & $\begin{array}{l}\text { Sebagian kecil } \\
\text { sudah } \\
\text { dimanfaatkan }\end{array}$ \\
\hline Sisa proses gula & $\begin{array}{l}\text { Jawa, Sumatera, } \\
\text { Kalimantan } \\
\text { Selatan }\end{array}$ & $\begin{array}{l}\text { Bagase : } 10 \\
\text { Daun : } 9,6\end{array}$ & 78 & $\begin{array}{l}\text { Bagase umumnya } \\
\text { sudah digunakan } \\
\text { di pabrik gula } \\
\text { dalam bentuk } \\
\text { briket untuk } \\
\text { tungku boiler }\end{array}$ \\
\hline Sisa padi & $\begin{array}{l}\text { Jawa, Sumatera, } \\
\text { Sulawesi, } \\
\text { Kalimantan, } \\
\text { Bali/Nusa } \\
\text { Tenggara }\end{array}$ & $\begin{array}{l}\text { Bagase : } 10 \\
\text { Daun : } 9,6\end{array}$ & 150 & $\begin{array}{l}\text { Umumnya } \\
\text { dibakar di sawah, } \\
\text { pemanfaatan lain } \\
\text { masih terbatas }\end{array}$ \\
\hline Sisa kelapa & $\begin{array}{l}\text { Sumatera, Jawa, } \\
\text { Sulawesi }\end{array}$ & $\begin{array}{l}\text { Sekam : } 12 \\
\text { Batang : } 2 \\
\text { Jerami : } 49\end{array}$ & 7 & $\begin{array}{l}\text { Pemanfaatan } \\
\text { terbatas sebagai } \\
\text { kayu bakar dan } \\
\text { produksi arang }\end{array}$ \\
\hline Sisa sawit & $\begin{array}{l}\text { Sumatera, } \\
\text { Kalimantan, } \\
\text { Sulawesi, } \\
\text { Maluku, Nusa } \\
\text { Tenggara, Irian } \\
\text { Jaya }\end{array}$ & $\begin{array}{c}\text { TKKS : } 3,4 \\
\text { Serabut : } 3,6 \\
\text { Cangkang : } 1,2\end{array}$ & 67 & $\begin{array}{l}\text { Sebagiannya } \\
\text { sudah digunakan } \\
\text { sebagai sumber } \\
\text { energi, pupuk, } \\
\text { dan sebagiannya } \\
\text { dibuang }\end{array}$ \\
\hline
\end{tabular}

Sumber : Abdullah (2002) 
Tabel 2. Potensi biomasa nasional berdasarkan ketersediaan bahan baku

\begin{tabular}{|c|c|c|c|c|c|}
\hline No & Nasional & Unit & $\begin{array}{l}\text { Ketersediaan } \\
\text { bahan baku } \\
\text { (ton) }\end{array}$ & $\begin{array}{l}\text { Potensi energi } \\
\text { (GJ) }\end{array}$ & $\begin{array}{l}\text { Potensi } \\
\text { Umum } \\
(\mathrm{MWe})\end{array}$ \\
\hline \multirow[t]{7}{*}{1.} & Kelapa sawit & & & & \\
\hline & Serat (fiber) & ton & 12.830 .950 & 180.778 .665 & 1.231 \\
\hline & Cangkang (shell) & ton & 6.136 .541 & 108.861 .141 & 759 \\
\hline & Tandan kosong (EFB) & ton & 23.988 .298 & 118.757 .608 & 827 \\
\hline & Limbah cair (POME) & $\mathrm{m}^{3}$ & 47.995 .674 & 34.903 .142 & 430 \\
\hline & Pelepah & ton & 75.517 .083 & 1.063.384.453 & 8.430 \\
\hline & Tanam Ulang (Pelepah dan batang) & ton & 8.412 .853 & 123.280 .262 & 977 \\
\hline \multirow[t]{3}{*}{2.} & Tebu & & & & \\
\hline & Ampas tebu (bagasse) & ton & 9.559 .395 & 73.470 .505 & 582 \\
\hline & Daun dan pucuk tebu & ton & 7.154 .403 & 89.862 .170 & 712 \\
\hline \multirow[t]{2}{*}{3.} & Karet & & & & \\
\hline & Tanam ulang (batang dan ranting) & ton & 19.039 .860 & 350.747 .462 & 2.781 \\
\hline \multirow[t]{3}{*}{4.} & Kelapa & & & & \\
\hline & Sabut kelapa & ton & 1.119 .301 & 15.464 .755 & 119 \\
\hline & Tempurung kelapa & ton & 383.760 & 13.262 .989 & 59 \\
\hline \multirow[t]{3}{*}{5.} & Padi & & & & \\
\hline & Sekam & ton & 13.016 .712 & 180.592 .857 & 1.432 \\
\hline & Jerami & ton & 90.370 .365 & 1.056 .602 .982 & 8.376 \\
\hline \multirow[t]{3}{*}{6.} & Jagung & & & & \\
\hline & Tongkol & ton & 4.263 .116 & 62.470 .849 & 495 \\
\hline & Batang dan daun & ton & 14.920 .906 & 156.177 .123 & 1.238 \\
\hline \multirow[t]{2}{*}{7.} & Ubi kayu & & & & \\
\hline & Limbah cair & $\mathrm{m}^{3}$ & 111.796 .967 & 10.089 .673 & 271 \\
\hline \multirow[t]{3}{*}{8.} & Kayu & & & & \\
\hline & Lindi hitam (black liquor) & ton & 7.967 .045 & 110.076 .196 & 955 \\
\hline & Limbah kayu & ton & 2.672 .782 & 49.348 .299 & 380 \\
\hline \multirow[t]{2}{*}{9.} & Sapi & & & & \\
\hline & Kotoran & ton & 53.782 .761 & 35.496 .619 & 535 \\
\hline \multirow[t]{4}{*}{10.} & Sampah kota & & & & \\
\hline & Sampah organik basah & ton & 18.499 .755 & & \\
\hline & Refuse derived fuel & ton & 9.816 .034 & 260.649 .740 & 2.066 \\
\hline & Total Nasional & & & 4.094.277.399 & 32.654 \\
\hline
\end{tabular}

Sumber : Direktorat Bioenergi (2013) 


\section{Potensi Pemanfaatan Lignoselulosa}

Biomasa lignoselulosa yang banyak terdapat pada tanaman hutan, tanaman perkebunan dan tanaman pangan dapat diurai menjadi lignin, selulosa dan hemiselulosa melalui tahap pra perlakuan dengan berbagai metode. Lignin, selulosa dan hemiselulosa melalui serangkaian proses tertentu akan menghasilkan bio-based product yang berbahan dasar lignin dan glukosa. Pemanfaatan sumber lignoselulosa dari biomasa tanaman berkayu, baik perkebunan maupun kehutanan, dinilai lebih potensial karena dapat mengurangi terjadinya kompetisi penggunaan lahan dan produk dengan kebutuhan pangan dan pakan.

Pemanfaatan lignoselulosa sejak bahan dasar hingga pecahan ukuran nano sangat luas. Potensi produk yang bisa dihasilkan dari biomasa lignoselulosa antara lain bioenergi terbarukan, gas berbasis sumberdaya biologi (bio-based fuel gas), biogas, hingga minyak berbasis biomasa (bio-oil) yang berpotensi digunakan dalam industri kimia, makanan dan obat-obatan. Sekilas proses menuju produk akhir dapat dilihat pada Gambar 1 (Ruamsook \& Thomchick, 2014).

Selulosa yang terpisah dari lignoselulosa juga dapat dijadikan sebagai bahan bioplastik, sementara lignin dapat dijadikan sebagai bahan alternatif untuk substitusi fenol pada pembuatan perekat kayu dengan emisi formaldehida yang rendah. Komponen lignin juga sangat berpotensi menjadi bahan baku untuk memproduksi senyawa aromatik, seperti BTX (benzena, toluen, etilen, dan xilen) dan turunannya (Cheng et al., 2017). Lignin juga dapat dimanfaatkan sebagai zat aditif yang berfungsi sebagai plasticizer dan water reducer pada pembuatan mortar dan

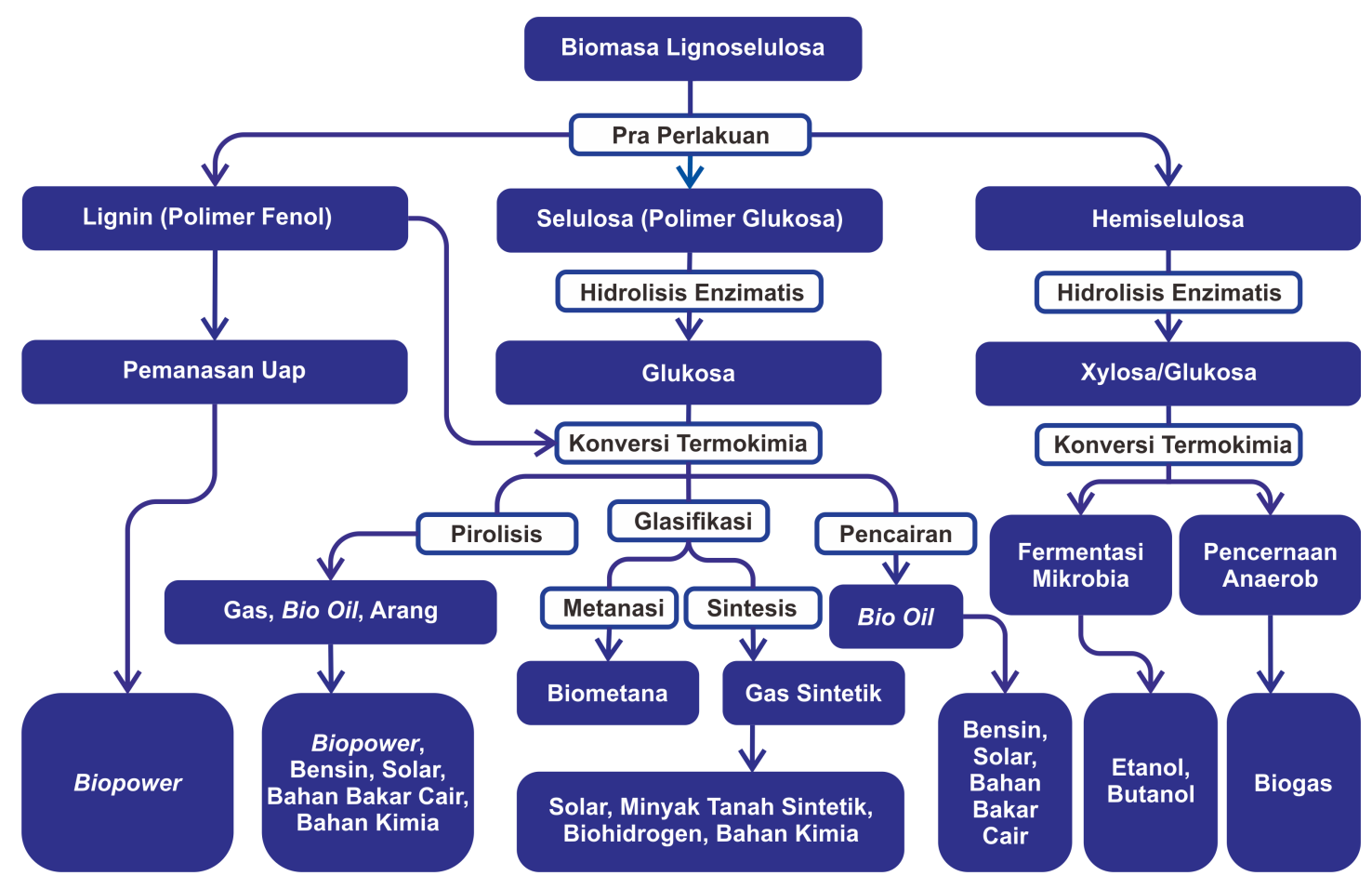

Keterangan : biopower (sumber tenaga berbasis biomasa) bio-oil (bahan bakar minyak berbasis biomasa)

Sumber : Ruamsook \& Thomchick (2014)

Gambar 1. Potensi produk yang bisa dihasilkan dari biomasa lignoselulosa 
beton, karena diduga dapat meningkatkan sifat fisik dan mekanik adukan semen (mortar) (Falah, 2012). Produk-produk turunan lignin juga dapat dimanfaatkan sebagai bahan bakar, pelarut kimia, dan polimer(Singh et al., 2014).

Perubahan serat selulosa menjadi nanoselulosa juga dapat dimanfaatkan sebagai filler penguat polimer, penguat membran, pengental untuk dispersi dan media pembawa obat (Ioelovich, 2012). Keunggulan serat lignoselulosa dibandingkan serat sintetik disajikan pada Tabel 3 (Kaczmar et al., 2007). Lignoselulosa berbasis nanoteknologi bahkan membuka peluang dimanfaatkan untuk berbagai produk dalam industri seperti kemasan, biomedis, elektronik, optik dan pertanian. Nanokomposit berbasis selulosa akan menjadi salah satu alternatif untuk memenuhi kebutuhan bahan material yang lebih baik pada masa depan, salah satunya bioplastik. Keunggulan nanokomposit dari serat alam antara lain mudah diperoleh, densitas rendah, kuat, fleksibel, terbarukan dan dapat terurai secara alami. Inilah yang menjadikan alasan mengapa para peneliti lebih menyukai dan memilih nanofiber untuk membuat komposit. Leao dari Sao Paulo State University, Brazil, menjelaskan keunggulan serat nanoselulosa antara lain $30 \%$ lebih ringan namun tiga sampai empat kali lebih kuat dibandingkan serat plastik konvensional. Selain itu, plastik berbahan serat nanoselulosa memiliki keunggulan mekanis berupa daya tahan yang lebih tinggi dari kerusakan yang disebabkan panas, tumpahan bahan bakar, air, dan oksigen (National Geographic Indonesia, 2011). Serat selulosa menjadi bahan yang sangat kompetitif, dan karena diameternya yang tipis, selulosa dapat dimanfaatkan sebagai serat penguat untuk komposit, untuk mengurangi bobot kendaraan dalam industri otomotif, serta untuk berbagai aplikasi elektronik dan medis(Malkki, 2017).

\section{Potensi Pemanfaatan Lignoselulosa dari Biomasa Kayu Karet}

\section{A. Bioetanol}

Salah satu produk hasil biomasa lignoselulosa yang banyak diteliti ialah pemanfaatannya untuk menghasilkan bioenergi terbarukan, seperti bioetanol. Bioetanol merupakan salah satu biofuel yang hadir sebagai bahan bakar alternatif yang lebih ramah lingkungan dan sifatnya yang terbarukan. Bioetanol merupakan cairan tidak berwarna yang mudah terdegradasi, rendah toksisitas dan memiliki peluang yang kecil untuk menyebabkan pencemaran lingkungan ketika tumpah "' (Chin \& Hng, 2013). Penggunaan biomasa sebagai bahan baku energi akan sangat berperan dalam menurunkan emisi gas rumah kaca, karena $\mathrm{CO}_{2}$ yang dilepaskan dari degradasi biomasa alam akan tersedia sebagai karbon sehingga meniadakan emisi gas rumah kaca. Dalam laporan EPA Emission Fact, bioetanol yang diproduksi dari biomasa berpotensi memutus siklus emisi gas rumah kaca hingga $86 \%$

Tabel 3. Perbedaan karakteristik serat lignoselulosa dan serat sintetis

\begin{tabular}{lll}
\hline \multicolumn{1}{c}{ Karakteristik } & \multicolumn{1}{c}{ Serat lignoselulosa } & \multicolumn{1}{c}{ Serat sintetik } \\
\hline Terbarukan & Ya & Tidak \\
Kasar & Tidak & Ya \\
Mudah terdegradasi & Ya & Tidak \\
Biaya & Murah & Mahal \\
Kerapatan & Rendah & Tinggi \\
Gangguan Lingkungan & Tidak ada & Berpotensi \\
Modulus Young & Tinggi (138 GPa) & Rendah $(65 \mathrm{GPa})$ \\
Ekspansi termal & Koefisien rendah & Koefisien $\mathrm{t}$ inggi \\
\hline
\end{tabular}

Sumber : Kaczmar et al. (2007) 
dibandingkan bahan bakar minyak (Mohajan, 2012). Pangsa pasar energi baru terbarukan diperkirakan akan meningkat dari $8 \%$ menjadi $10 \%$ pada 2050 atau tumbuh $6 \%$ per tahun. Jenis energi baru terbarukan yang akan tumbuh pesat ialah panas bumi, hidro dan biomasa komersial (Dewan Energi Nasional, 2014).

Tanaman karet memiliki kandungan selulosa mencapai $42 \%$ dan hemiselulosa sekitar $21 \%$, secara teoritis dapat menghasilkan sekitar 0.32 gram etanol per gram kayu atau 0,63 gram holoselulosa murni (Razar \& Aris, 2012). Potensi produk kayu menjadi sumber bioenergi bisa diperkirakan berdasarkan nilai residunya yaitu rasio residu tanaman (crop-to residue ratio/CRR), faktor ketersediaan (surplus availability factor/SAF) dan nilai pemanasan terendah (lower heating value/LHV). Berdasarkan potensi bioenergi yang dihasilkan dari residu kayu karet, eukaliptus dan kelapa sawit di Thailand (Tabel 4), kayu karet menunjukkan potensi yang cukup bagus untuk diproses menjadi bioenergi (Laohalidanond et al., 2006). Hasil kajian "'Chin \& Hng (2013) pada potensi bioetanol per ton untuk batang kelapa sawit, kayu karet dan campuran kayu keras beserta efisiensi konversinya menunjukkan bahwa konversi tertinggi diperoleh dari batang kelapa sawit $(66 \%)$, diikuti oleh campuran kayu keras $(60 \%)$ dan kayu karet (57\%) (Tabel 5). Beberapa data tersebut menunjukkan adanya potensi yang cukup baik dari biomasa kayu karet untuk diproses menjadi sumber energi terbarukan di masa depan.

Tabel 4. Potensi biomasa kayu karet, eukaliptus dan kelapa sawit untuk diproses menjadi bioenergi

\begin{tabular}{llccccc}
\hline Sumber & Residu & $\begin{array}{c}\text { Rasio } \\
\text { residu } \\
\text { tanaman }\end{array}$ & $\begin{array}{c}\text { Faktor } \\
\text { ketersediaan }\end{array}$ & $\begin{array}{c}\text { Nilai } \\
\text { pemanasan } \\
\text { terendah } \\
(\mathrm{kJ} / \mathrm{kg})\end{array}$ & $\begin{array}{c}\text { Potensi } \\
\text { (ton/tahun })\end{array}$ & $\begin{array}{c}\text { Potensi } \\
(\mathrm{GJ} / \text { tahun })\end{array}$ \\
\hline Karet & Kayu & 0,20 & 1 & 13,962 & $1.373,44$ & 19,18 \\
& Kulit kayu & 0,40 & 1 & - & $2.746,89$ & 38,35 \\
Eukaliptus & Kayu & - & 0 & 6,300 & 0 & 0 \\
Kelapa & Kulit kayu & 1,0 & 0,50 & - & $4.649,25$ & 29,29 \\
sawit & Tandan & 2,60 & 1 & 7,540 & $14.355,86$ & 108,24 \\
\hline
\end{tabular}

Sumber : Laohalidanond et al. (2006)

Tabel 5. Perbandingan efisiensi bioetanol dari kelapa sawit, kayu karet dan campuran kayu keras

\begin{tabular}{lccc}
\hline \multicolumn{1}{c}{ Perbandingan } & Batang kelapa sawit & $\begin{array}{c}\text { Kayu karet } \\
\text { Campuran kayu } \\
\text { keras }\end{array}$ \\
\hline Kandungan selulosa & 0,48 & 0,56 & 0,56 \\
Efisiensi hidrolisis & 0,82 & 0,67 & 0,66 \\
Hasil etanol teoritis pada efisiensi & 0,51 & 0,51 & 0,51 \\
fermentasi 100\% & & & \\
Efisiensi ak tual fermentasi & 0,80 & 0,85 & 0,90 \\
Hasil ak tual etanol/ton bahan kering (L) & 240 & 206 & 215 \\
Hasil teoritis etano 1/ton bahan kering (L) & 310 & 362 & 361 \\
Total efisiensi konversi etanol (\%) & 66 & 57 & 60 \\
\hline
\end{tabular}

Sumber : Chin \& Hng (2013) 
Penelitian terkait proses produksi bioetanol dari bahan yang mengandung lignoselulosa telah banyak dilakukan. Proses tersebut meliputi perlakuan pendahuluan (pretreatment), fermentasi hingga pemurnian alkohol. Selama beberapa tahun terakhir berbagai teknik perlakuan pendahuluan telah dipelajari melalui pendekatan biologi, fisika dan kimia. Alhassan (2010) telah mencoba beberapa perlakuan pendahuluan pada kayu karet, dan hasilnya menunjukkan bahwa kombinasi asam nitrat dan sodium hidroksida cukup efektif untuk meningkatkan hidrolisis enzimatik. Pada proses hidrolisis menggunakan asam sulfur, efisiensi hasil konversi selulosa menjadi glukosa masingmasing sebesar 82\%, 67\% dan 66\% untuk kelapa sawit, karet dan campuran kayu keras '(Chin et al., 2010). Hanya saja perlakuan pendahuluan secara fisik dan kimia memerlukan perlakuan temperatur tinggi dan asam atau alkali, yang dapat merusak lignoselulosa atau menghasilkan produk inhibitor, untuk itu perlakuan secara biologi menggunakan mikroba dianggap lebih efisien. Studi selanjutnya menggunakan Saccharomyces cerevisiae, efisiensi hidrolisis mencapai $80 \%$, $85 \%$ dan $90 \%$ masing-masing untuk kelapa sawit, kayu karet dan campuran kayu keras ' (Chin et al., 2011). Selain Saccharomyces cerevisiae, mikroba jenis jamur pelapuk putih juga cukup potensial untuk perlakuan pendahuluan kayu karet secara biologi, seperti Ceriporiopsis subvermispora dan Trametes versicolor(Nazarpour et al., 2013).

Pengembangan bahan yang mengandung lignoselulosa untuk produksi bioetanol masih menemui beberapa kendala. Kendala tersebut seperti rendemen bioetanol yang masih rendah, biaya produksi yang tinggi, dan kehadiran zat penghambat (inhibitor) yang dapat mengurangi fermentabilitas selulosa dan hemiselulosa menjadi etanol. Penelitian perlu diarahkan pada optimalisasi teknologi terutama pada proses perlakuan pendahuluan (pretreatment), hidrolisis (sakarifikasi) dan fermentasi. Penelitian juga bisa diarahkan untuk mengembangkan enzim yang lebih efisien dari mikroorganisme tertentu. Metode fermentasi terbaik dengan enzim tertentu juga perlu diteliti lebih lanjut untuk mendapatkan kadar etanol yang optimal, termasuk kemungkinan pemanfaatan kayu karet yang terserang jamur akar putih. Tidak kalah penting ialah pengembangan teknologi konversi yang lebih efisien untuk mendukung pengembangan skala massal.

\section{B. Bahan Pendukung Pertanian}

Peluang lain dalam pemanfaatan lignoselulosa adalah untuk menghasilkan produk yang mendukung sarana pertanian, seperti media tanam, pupuk, biopestisida, dekomposer maupun pakan ternak. Salah satu yang dapat dimanfaatkan sebagai media tanam adalah bioarang. Bioarang sebagai media pengganti tanah memiliki beberapa keunggulan, seperti dapat mengurangi pencucian nitrogen oleh air tanah, meningkatkan kapasitas tukar kation, menetralisir $\mathrm{pH}$ tanah, meningkatkan ketersediaan air, dan meningkatkan mikroba tanah yang menguntungkan (Ruamsook \& Thomchick, 2014). Bioarang juga dapat meningkatkan kapasitas menahan air tanah, sehingga mengurangi kehilangan air dan efisien dalam pengairan. Bioarang juga dapat meningkatkan aerasi dan memperlambat kehilangan nutrisi (NPK) sehingga mengurasi kebutuhan pupuk. Bioarang sebagai salah satu penambah komposisi media tanam dapat diproduksi melalui proses pirolisis. Bioarang berbahan dasar serbuk kayu karet atau RWSD (rubber wood sawdust) terbukti dapat digunakan sebagai pengganti tanah(Shaaban et al., 2014). Bioarang berbahan RWSD juga terbukti sangat potensial digunakan di banyak tipe tanah untuk meningkatkan daya hasil tanaman (Shaaban et al., 2013). Aplikasi bioarang berbahan kayu karet saja sebesar $2 \% \mathrm{w} / \mathrm{w}$ pada batang bawah karet mampu meningkatkan bobot kering tanaman hingga $81 \%$, sedangkan aplikasi dengan penambahan pupuk $\mathrm{N}-\mathrm{Mg}$ meningkatkan pertumbuhan batang bawah sebesar $29 \%$ dan bibit klonal $61 \%$ dibandingkan hanya aplikasi pupuk N-P-KMg saja (Dharmakeerthi et al., 2012). RWSD 
kayu karet juga potensial untuk memproduksi karbon aktif. Karbon aktif adalah adsorben organik yang antara lain dapat digunakan untuk menyerap zat polutan. Karbon aktif dari bahan RWSD terbukti mampu menyerap senyawa gas dan cairan seperti benzena dan trikloroetilen secara efisien (Mazlan et al., 2016).

Lignin dan produk berbasis lignin dapat berperan penting dalam rehabilitasi tanah, pembuatan pupuk slow release, bahan pengompos, meningkatkan humus, stabilisasi tanah, insektisida dan pellet untuk pakan ternak (The International Lignin Institute, 2018). Hanya saja belum banyak penelitian terkait pemanfaatan lignin yang berasal dari biomasa kayu karet untuk kebutuhan bahan pendukung pertanian.

\section{Industri Obat, Makanan dan Komponen Kimia}

Lignin sebagai bagian komponen lignoselulosa, juga dapat dimanfaatkan dalam industri obat-obatan, makanan dan pembuatan komponen kimia. Lignin berhasil diisolasi dari kayu karet menggunakan cairan ionik (1,3-dimethylimidazolium methylsulfate) (Shamsuri \& Abdullah, 2010). Lignosulfonat, produk turunan dari lignin, dapat digunakan sebagai emulsifier pada beberapa produk seperti pestisida, emulsi aspal, bahan pewarna dan pencelup, emulsi lilin, vitamin, dan mikronutrien (The International Lignin Institute, 2018). Komponen yang pertama kali diekstrak dari bio-oil saat proses pirolisis dapat digunakan sebagai bahan tambahan makanan, seperti bahan perasa dan aroma. Komponen kimia cair yang diproduksi melalui proses pirolisis antara lain kelompok senyawa fenol (fenol, catekol, guaiakol, siringol, kresols); aldehid (vanilin, siringaldehid); dan alifatik (metana, etana, cabang alkana). Vanilin sering digunakan sebagai bahan perasa dan aroma pada industri obat-obatan, makanan, wewangian parfum dan produk pembersih.
Vanilin juga dapat digunakan sebagai bahan perantara (chemical intermediary) dalam industri farmasi. Vanilin berhasil diperoleh menggunakan lignin kayu karet melalui reaksi oksidasi media cair ionik 1,3dimethylimidazolium methylsulphate (Shamsuri \& Abdullah, 2012).

\section{Nanomaterial}

Nanoselulosa adalah bahan biomaterial berkelanjutan yang mudah terdegradasi dan terbarukan. Banyak ragam kegunaan dari material nanokomposit selulosa, baik untuk biomedis, kemasan, otomotif, elektronik, konstruksi dan aplikasi penyaring air. Nanoselulosa murni bersifat non toksik dan biokompatibel, yang potensial digunakan pada produk kesehatan, kosmetik dan biomedis. Modifikasi kimiawi dari selulosa dapat digunakan sebagai pembawa imobilisasi enzim yang menjanjikan atau produk obatobatan(Ruamsook \& Thomchick, 2014).

Serat dari selulosa kayu karet memiliki keuntungan antara lain tekstur yang baik, warna yang cerah, kekuatan cukup baik dan baik untuk properti mesin (Kim, 2013). Nanoselulosa dari biomasa kayu karet antara lain berhasil diperoleh melalui reaksi enzimatis dan perlakuan kimia yang dikombinasikan dengan perlakuan ultrasonik (Poddar et al., 2015; Kim, 2013) atau sonikasi dan perlakuan homogenisasi tekanan tinggi (Poddar et al., 2016) yang selanjutnya dapat digunakan sebagai bio-nanokomposit.

\section{Kesimpulan}

Biomasa kayu karet tua mengandung lignoselulosa yang cukup tinggi, yaitu selulosa, hemiselulosa dan lignin. Lignoselulosa dari biomasa kayu karet dapat dimanfaatkan untuk menghasilkan sumber energi (bioetanol), bahan pendukung pertanian (bioarang, biopestisida, pakan ternak), industri obat, makanan dan bahan kimia (vanilin, zat 
tambahan makanan, bahan kemasan), dan nanoselulosa (nanokomposit). Perlu dukungan penelitian, pengembangan, teknologi dan arah kebijakan yang tepat untuk memanfaatkan potensi biomasa kayu karet, menuju industri masa depan yang lebih ekonomis, massal, ramah lingkungan dan terbarukan.

\section{Daftar Pustaka}

Abdullah, K. (2002). Biomass energy potentials and utilization in Indonesia. Diakses dari https://www.researchgate.net/publication /228402035_Biomass_Energy_Potentials_ And_Utilization_In_Indonesia.

Alhassan, M. A. (2010). Chemical pretreatment of rubber wood for enzymatic saccharification in bioethanol production. (Master Thesis), Universiti Putra Malaysia, Serdang, Selangor.

Badan Pusat Statistik. (2015). Statistik produksi kehutanan. Jakarta: Badan Pusat Statistik.

Cheng, C., Wang, J., Shen, D., Xue, J., Guan, S., Gu, S., \& Luo, K. H. (2017). Catalytic oxidation of lignin in solvent systems for production of renewable chemicals: A review. Polymers, 9(6), 1-25. doi:10.3390 /polym 9060240

Chin, K., H'ng, P., Wong, L., Tey, B., \& Paridah, M. (2010). Optimization study of ethanolic fermentation from oil palm trunk, rubberwood and mixed hardwood hydrolysates using Saccharomyces cerevisiae. Bioresour Technol, 101(9), 32873291.

Chin, K., H'ng, P., Wong, L., Tey, B., \& Paridah, M. (2011). Production of glucose from oil palm trunk and sawdust of rubberwood and mixed hardwood. Applied energy, 88(11), 4222-4228.

Chin, K. L., \& H'ng, P. S. (2013). A Real Story of Bioethanol from Biomass: Malaysia Perspective. In M. D. Matovic (Ed.), Biomass Now. Rijeka: InTech.
Dewan Energi Nasional. (2014). Outlook Energi Indonesia 2014. Jakarta: Dewan Energi Nasional, Kementerian Energi dan Sumberdaya Mineral.

Dharmakeerthi, R. S., Chandrasiri, J. A. S., \& Edirimanne, V. U. (2012). Effect of rubber wood biochar on nutrition and growth of nursery plants of Hevea brasiliensis established in an Ultisol. SpringerPlus, 1(1), 84. doi:org/10.1186/2193-1801-1-84

Direktorat Bioenergi. (2013). Panduan pengguna untuk pasokan sektor bioenergi. Jakarta, Indonesia: Direktorat Bioenergi, Kementerian Energi dan Sumberdaya Mineral.

Direktorat Jenderal Perkebunan. (2016). Statistik perkebunan Indonesia : karet 2015 2017. Jakarta, Indonesia: Direktorat Jenderal Perkebunan, Kementerian Pertanian.

Falah, F. (2012). Pemanfaatan limbah lignin dari proses pembuatan bioetanol dari tkks sebagai bahan aditif pada mortar. (Tesis), Universitas Indonesia, Jakarta.

Ioelovich, M. (2012). Optimal conditions for isolation of nanocrystalline cellulose particles. Nanoscience and Nanotechnology, 2(2), 9-13. doi:10.5923/j.nn.20120202.03

Kaczmar, J., Pach, J., \& Kozlowski, R. (2007). Use of natural fibres as fillers for polymer composites. International Polymer Science and Technology, 34(6), T45.

Kementerian Pertanian. (2016). Outlook Karet: Komoditas Pertanian Subsektor Perkebunan (Vol. ). Jakarta, Indonesia: Pusat Data dan Sistem Informasi Pertanian, Sekretariat Jenderal Kementerian Pertanian.

Killmann, W. (2001). Forest Plantations Thematic Papers : Non-Forest Tree Plantation. Rome, Italy: Forestry Department, Food and Agriculture Organization of the United Nations.

Kim, N. G. S. (2013). Synthesis of nanocellulose from rubberwood fibers. (Doctoral Thesis), Universiti Malaysia Pahang, Pahang. 
Laohalidanond, K., Heil, J., \& Wirtgen, C. (2006). The production of synthetic diesel from biomass. KMITL Science and Technology Journal, 6(1), 35-45.

Malkki, Y. (2017). Nanocellulose and Chemicals from by-Products and Waste. MOJ Food process Technol, 4(1), 1-3.

Mazlan, M. A. F., Uemura, Y., Yusup, S., Elhassan, F., Uddin, A., Hiwada, A., \& Demiya, M. (2016). Activated carbon from rubber wood sawdust by carbon dioxide activation. Procedia engineering, 148, 530537.

Mohajan, H. K. (2012). Greenhouse Gas Emissions of the USA. Indus Journal of Management \& Social Sciences, 6(2), 132-148.

Nancy, C., Agustina, D. S., \& Syarifa, L. F. (2013). Potensi Kayu Hasil Peremajaan Karet Rakyat untuk Memasok Industri Kayu Karet : Studi Kasus di Provinsi Sumatera Selatan. Jurnal Penelitian Karet, 31(1), 68-68.

National Geographic Indonesia. (2011, 30 Maret 2011). Plastik Nanoselulosa untuk Mobil Masa Depan. Diakses dari http://nationalgeographic.co.id/berita/20 $11 / 03$ /plastik-nanoselulosa-untuk-mobilmasa-depan.

Nazarpour, F., Abdullah, D. K., Abdullah, N., Motedayen, N., \& Zamiri, R. (2013). Biological pretreatment of rubberwood with Ceriporiopsis subvermispora for enzymatic hydrolysis and bioethanol production. BioMed research international, 2013, 1 - 9. doi:10.1155/2013/268349

Poddar, P. K., Gupta, A., Jamari, S. S., Kim, N. S., Khan, T. A., Sharma, S., \& Aziz, M. A. A. (2015). Synthesis of nanocellulose from rubberwood fibers via ultrasonication combined with enzymatic and chemical pretreatments. Asian Journal of Applied Sciences, 3(5), 520-527.
Poddar, P. K., Gupta, A., Jamari, S. S. B., Rashid, S. S., Sharma, S., Subramaniam, M., \& Thraisingam, J. (2016). Isolation of Nano Cellulose from Rubber Wood Fibre and Fibrillation Effects on Nano Cellulose Reinforced Poly (Ethylene Oxide). Tulisan disajikan pada The National Conference for Postgraduate Research 2016, Pahang.

Razar, R. M., \& Aris, M. N. (2012, 4th - 6th September ). Utilization of lignocellulosic materials from unused plant parts of rubber tree during replanting to reduce the potential of root diseases attack. Tulisan disajikan pada 3rd International Plantation Industry Conference and Exhibition, Kota Kinabalu.

Ruamsook, K., \& Thomchick, E. (2014). Market Opportunity Lignocellulosic. Pennsylvania, USA: Department of Supply Chain and Information Systems, Smeal College of Business, Pennsylvania State University.

Shaaban, A., Se, S.-M., Dimin, M., Juoi, J. M., Husin, M. H. M., \& Mitan, N. M. M. (2014). Influence of heating temperature and holding time on biochars derived from rubber wood sawdust via slow pyrolysis. Journal of Analytical and Applied Pyrolysis, 107, 31-39. doi:org/10.1016/j.jaap.2014 .01 .021

Shaaban, A., Se, S.-M., Mitan, N. M. M., \& Dimin, M. (2013). Characterization of biochar derived from rubber wood sawdust through slow pyrolysis on surface porosities and functional groups. Procedia engineering, 68(56), 365-371.

Shamsuri, A. A., \& Abdullah, D. K. (2010). Isolation and characterization of lignin from rubber wood in ionic liquid medium. Modern Applied Science, 4(11), 19-27.

Shamsuri, A. A., \& Abdullah, D. K. (2012). A Preliminary study of oxidation of lignin from rubber wood to vanillin in ionic liquid medium. Oxidation Communications, 35(3), 767-775. 
Singh, R., Prakash, A., Dhiman, S. K., Balagurumurthy, B., Arora, A. K., Puri, S., \& Bhaskar, T. (2014). Hydrothermal conversion of lignin to substituted phenols and aromatic ethers. Bioresour Technol, 165, 319-322.

The International Lignin Institute. (2018, 25 April 2018). About lignin. Diakses dari http://www.ili-lignin.com/aboutlignin .php
Woelan, S., Sayurandi, S., \& Pasaribu, S. A. (2012). Potensi kayu karet hasil peremajaan di tingkat perusahaan perkebunan. Warta Perkaretan, 31(2), 75-85. 